Parker, I."Teoria Social Lacaniana e Prática Clínica”

\title{
TEORIA SOCIAL LACANIANA E PRÁTICA CLÍNICA ${ }^{1}$
}

\author{
Ian Parker \\ Manchester Metropolitan University
}

RESUMO: O encontro intelectual entre três escritores simpáticos, em algum nível, ao trabalho de Lacan foi reunido no livro Contingência, Hegemonia, Universalidade (Butler, Laclau e Zizek, 2000a). Esses três autores são bem conhecidos em um conjunto difuso de campos que vão dos "estudos culturais" (cultural studies) à teoria literária e à teoria política. Como o subtítulo do livro indica - "Diálogos Contemporâneos da Esquerda" - eles também possuem alguma afinidade com o marxismo, "pós-marxismo" e política feminista. Uma questão que este debate entre três pensadores da teoria social lacaniana freqüentemente recoloca diz respeito à possibilidade de articular a teoria lacaniana com a política radical. No presente artigo discute-se se há implicações clínicas para esta leitura proposta pela esquerda Lacaniana, na qual os três autores estão engajados. Tomando como ponto de confluência o livro acima, o objetivo trabalho é mostrar como a prática política e a prática clínica encontram certos pontos de congruência em torno de temas como a negatividade, a sexualidade e a subversão do sujeito.

PALAVRAS-CHAVE: Teoria social Lacaniana - prática clínica - prática política

\section{LACANIAN SOCIAL THEORY AND CLINICAL PRACTICE}

ABSTRACT: An intellectual encounter between three writers sympathetic to some degree with Lacan's work has been recorded in the book Contingency, Hegemony, Universality (Butler, Laclau and •i•ek, 2000a). These three writers are well known in the overlapping collection of fuzzy sets "cultural studies", "literary theory" and "political theory", and, as the subtitle of the book "Contemporary Dialogues on the Left" indicates, they also have some sympathy with Marxist, "post-marxist" or feminist politics. One question that the debate between the three often returns to is whether it is possible to articulate Lacanian theory with radical politics. However, another question that is embedded in the encounter but which is only obliquely addressed is whether there are clinical implications for the kind of leftist readings of Lacan that these three writers engage in. I focus on that question in this paper.

KEY-WORDS: Lacanian social theory - clinical practice - politics practice 
Psicologia \& Sociedade; 14 (2): 48-73; jul./dez.2002

\section{INTRODUÇÃO}

Lacan tem desenvolvido uma reputação, majoritariamente entre o público anglófono, como um "teórico social", para alguns leitores apenas uma fonte para crítica de cinema. Isso tem significado que seus trabalhos clínicos, como psicanalista, permanecem obscuros (Burgin, Donald \& Kaplan, 1986; MacCannell, 1986, Macey, 1988). A atual prática da psicanálise lacaniana tem sido assumida como possuindo pequena importância para a forma como "o social" deve ser especificado e para a forma como a transformação política pode ser visada. O recente movimento para recuperar as descrições e especulações clínicas de Lacan, o foco primário de seu trabalho, tem como consequiência, caído na armadilha de apresentar um Lacan que fala sobre a análise, mas não muito sobre cultura (Fink, 1997; Nobus, 2000; Leader, 1996,1997). Mas talvez agora seja possível divisar mais claramente uma "Teoria Social Lacaniana" que tentou flutuar livre da prática clínica, tal como se exemplifica na troca entre Butler, Laclau e Zizek, e que pode retornar ao solo da prática novamente.

\section{PSICANÁLISE E SUBVERSÃO}

Muitas tentativas de traduzir a psicanálise da esfera do individual, ao qual concerne a maior parte da prática clínica, para a esfera do social, ao qual a política da psicanálise está endereçada, são apanhadas em um dualismo entre o individual e o social que reproduz cada esfera como separada e auto-suficiente (Henriques, 1984). Quando o social é tratado como uma coleção de indivíduos, aos quais a teoria psicanalítica pode ser fácil e diretamente aplicada, a retradução traz de volta noções de patologia individual e técnica clínica, que são desinteressantes e até mesmo banais, mesmo para o analista. Este movimento de dupla tradução costuma trazer elementos de "psicanálise selvagem" que introduzem pelo caminho novas idéias, por vezes frutíferas, mas sem grande consequiência para a transformação da relação conceitual entre o indivíduo e o mundo político (Young, 1994). Quando o social é tratado como um "indivíduo gigante", no qual operam seqüências de desenvolvimento e mecanismos de defesa, a tradução não é tão suave, e são necessárias modificações na teoria psicanalítica para que esta se retraduza ao trabalho clínico individual. Isso, por si só, já nos diz algo acerca da localização cultural da pessoa e suas implicações em processos psíquicos e políticos (Lasch, 1978). Em ambas as situações, o psíquico e o político são concebidos como interagindo, 
Parker, I. "Teoria Social Lacaniana e Prática Clínica"

dialeticamente talvez, mas como esferas autocontidas e antagônicas.

REPRESENTAÇÃO

O debate entre Butler, Laclau e Zizek gira em torno de uma nova forma de pensar este antagonismo e de como realocar este antagonismo no nível da representação. O problema (deadlock) da representação, que cada um deles toma como preocupação, e procura abrir um caminho alternativo, pode ser assim resumido: em vez que continuar a buscar uma teoria que estabeleça as relações de representação entre indivíduo e sociedade é necessário tomar esta relação problemática e insolúvel como ponto de partida constitutivo do campo social e do sujeito individual. O antagonismo entre individual e social torna-se então uma manifestação particular do impasse da representação e não sua força originária e definitiva. Zizek torna este ponto explícito em seu argumento contra Laclau, de que o antagonismo é "interno" ao sujeito $e$ ao social, e não algo que se ocorre entre eles.

Este projeto é crucial para qualquer tentativa de repensar ou de retrabalhar o entrelaçamento entre o "pessoal" e o "político" no quadro da política socialista, um problema insistente no socialismo feminista do final dos anos 70 (Zaretsky, 1976; Rowbotham, Segal e Wainwhright, 1979). Psicanálise aqui, sob os auspícios de Reich e outros autores vagamente associados a tradição da Escola de Frankfurt, refere-se desde a teoria das Relações de Objeto e, como que por extensão, Lacan. Esta família assim reunida surge no campo da opressão como um " refúgio em um mundo sem coração" que postula de forma ambivalente segurança e transformação no cerne dos sujeitos individuais (Mitchell, 1974; Lasch, 1978). A questão chave acerca da relação entre a pessoa e a transformação política torna-se crescentemente uma extensão do argumento de que toda transformação é intrinsecamente "terapêutica". O percurso que vai do engajamento político para a terapia, torna-se uma trajetória característica na esquerda desde os anos 70. Isso se torna um pano de fundo contra o qual as tentativas de politizar a experiência individual são colocadas e enredadas (Jacoby, 1973).

O que Butler, Laclau e Zizek fazem é um pouco diferente, precisamente porque seu ponto de partida para a questão, nesta intersecção entre o individual e o social, não se coloca no lado pessoal da equação mas do lado político. Os pontos de referência para o debate entre os três estão enraizados em diferentes concepções sobre quais devem ser as condições de possibilidade histórica e dinâmica da transformação política. Butler e 
$\overline{ }$ Psicologia \& Sociedade; 14 (2): 48-73; jul./dez.2002

Zizek estão trabalhando no terreno da filosofia hegeliana (contra o pósestruturalismo de Laclau e sua leitura de Gramsci). Mas apesar do nível de proximidade e contradição que Hegel admite Zizek e Laclau ainda tomam o marxismo como um ponto de partida (contra o apoio de Butler no solo feminista e na teoria pós-colonial). Zizek e Laclau discordam quanto à extensão das noções de verdade e ideologia, nos termos de um aprofundamento da leitura de Marx, ou de um giro ao "pós-marxismo". Finalmente Laclau e Butler situam-se a si mesmos no campo dos novos movimentos sociais (contra a aderência de Zizek a uma forma de leninismo), mas acusam-se mutuamente de uma regressão ao formalismo kantiano.

A "aporia da representação" também afeta o diálogo político do livro. Aqueles pontos em que aparece uma troca mais direta entre a psicanálise lacaniana e a política marxista, na contribuição de Zizek, são também, infelizmente, os domínios onde esta relação parece mais incompatível. Laclau queixa-se que, se é possível debater com Butler, no caso de Zizek:

"A única coisa que se pode obter dele são injunções para abandonar o capitalismo ou abolir as democracias liberais, que não possui nenhum sentido afinal." (Laclau, $2000 \mathrm{a}$, p. 205)

“... seu discurso é esquizofrenicamente dividido entre uma sofisticada análise lacaniana e um insuficientemente desconstruído marxismo tradicional. (Laclau, 200b, p. 205)”.

Pode-se ver, finalmente, uma partição dos caminhos que levaram talvez a uma aliança entre os dois autores, aliança que remonta às resenhas favoráveis de Zizek a Hegemonia e Estratégia Socialista (Laclau \& Mouffe, 1985) e a inclusão de escritos de Zizek (1990) no texto tardio de Laclau Reflexões sobre a Revolução de nosso Tempo (1990).

Agora Laclau declara que a sua "simpatia com a política de Zizek é largamente o resultado de uma miragem" (Laclau, 2000 a, p. 292). A resposta de Zizek se resume a insistir, após ser longamente provocado por Laclau, para que este defina exatamente qual programa político este estaria advogando. No entender de Zizek a "opção pelo impossível", defendida por Laclau, acaba implicando terror e mero exercício violento de poder. Seu tiro de misericórdia, no capítulo final do livro, está em afirmar que:

“... se esta escolha radical implica ser acusado publicamente 
Parker, I."Teoria Social Lacaniana e Prática Clínica”

de fazer parte da esquerda fascista (Linksfachismus) por alguns liberais de coração mole, então que assim seja !" (Zizek, 2000 a)

Esta diferença entre estratégia política e redução ao político é interessante, mas muito mais revelador é o comentário de Laclau de que o pensamento de Zizek não está organizado em torno de uma verdadeira reflexão política mas que é apenas discurso psicanalítico que toma seus exemplos do campo político ideológico (Laclau, 2000 a, p. 286). Logo, a questão é saber se existe, mais uma vez, uma divisão simples entre política e psicanálise, que explicará porque Zizek é tão digno de objeções por parte de Laclau, e em menor medida por Butler, ou se há algo na psicanálise genuína, e na prática psicanalítica in extremis, que poderia perturbar os "liberais de coração mole", incluindo aqueles favoravelmente propensos à psicoterapia. Mas para começar a responder esta pergunta temos que saber qual psicanálise está no terreno discursivo, mapeado pelo início deste debate.

\section{O INCONSCIENTE E A SEXUALIDADE}

Uma das mais curiosas características de Contingência, Hegemonia, Universalidade é que apesar das inúmeras referências a Lacan, quando somos convidados a dar um passo atrás e olhar para os antecedentes históricos e teóricos da psicanálise lacaniana os três escritores referem-se mais a Hegel do que a Freud.

Há inúmeras metáforas para a relação entre o plano individual e o que o ultrapassa que são evocadas por Butler, Laclau e Zizek, mas há pouquíssima discussão sobre o inconsciente. Zizek, por exemplo, cita a descrição hegeliana da planta como um animal com seus intestinos do lado de fora, em forma de raízes. Zizek reverte esta fórmula de modo a nos convidar a olhar para o ser humano como uma planta com as raízes para fora, recebendo nutrientes do simbólico: "não seria a ordem simbólica uma espécie de intestino espiritual do animal humano, fora de si ?" (Zizek, 2000 b, p.250). Esta interessante imagem não é usada, entretanto, para nos dizer algo mais sobre o inconsciente, que para os lacanianos, é claro, está intimamente ligado à ordem simbólica, mas é apenas um modo de, novamente, contornar Freud.

Esta imagem hegeliana da planta como um animal pode parecer psicanálise e isto introduz alguns aspectos da problemática da análise pes- 
Psicologia \& Sociedade; 14 (2): 48-73; jul./dez.2002

soal. Pode-se levantar o argumento de que a lógica hegeliana inclui uma insistência na atividade de reflexão do "espaço da razão", o que ressoa algo que prefigura a própria psicanálise ${ }^{2}$. Mas para lacanianos, tal linha de argumentação está distorcida desde o início. Nós começamos com Freud, não com Hegel. Existem temas claramente hegelianos, que são necessariamente partes do aparato teórico que Lacan traz em seu, Retorno a Freud, tais como a dialética do senhor-escravo, a bela alma e a dialética entre posição-suposição, mas tais temas desenvolvem-se nitidamente a serviço dos problemas freudianos.

Butler, Laclau e Zizek algumas vezes passam por conceitos freudianos como expressões pré-compreendidas, mas mais freqüentemente eles parecem felizes em ignorá-las ou substituí-las por outros elementos teóricos. Por exemplo, o termo recusa ${ }^{3}$ tem sido objeto de inúmeras controvérsias psicanalíticas em torno de seu estatuto e sentido na obra de Freud. No debate em questão ele é empregado como um mero sinônimo de negação.

Neste mesmo sentido vemos que a sexualidade tende a ser substituída por outros motivos quase-freudianos. Para Butler a diferença sexual é constituída através de processos discursivos culturalmente específicos e é em posições opostas que sexualidade e gênero são atuados. A performatividade do sexo é circunscrita a certos limites, mas é tarefa da teoria social radical e do ativismo - como o do movimento homossexual, que em certo momento anterior elegeu Butler (1990) como sua santa padroeira - romper estes limites.

Cada especificação teórica dos parâmetros em que esta subjetividade é constituída inclui uma visão do que precisa ser confrontado pelo sujeito em análise. Cada concepção de análise deverá estabelecer o que se torna possível, necessário, contingente ou impossível no seu interior. Em outras palavras limitar o escopo da ação é função da práxis psicanalítica. Butler, Laclau e Zizek parecem marcar a "impossibilidade" com uma extensionalidade que esta não possui. Ela assume um caráter diverso e polissêmico chegando-se assim a uma situação onde a impossibilidade ocupa o lugar e o foco do desejo sexual inconsciente em Freud.

\section{SUBVERSÃOE TEORIA POLÍTICA}

O trabalho de Freud foi um componente crucial e um motor para a tradição do iluminismo ocidental, e essa é precisamente uma das principais razões pelas quais a psicanálise coloca-se como radical. A psicanálise 
Parker, I.“Teoria Social Lacaniana e Prática Clínica”

é subversiva, e o reconhecimento disso é uma das pressuposições não explicitadas em Contingência, Hegemonia e Universalidade. Aqui é onde Lacan começa a se tornar realmente importante, porque o que sua leitura da psicanálise faz é trazer para a berlinda a radicalidade da experiência humana que Freud revelou. Nesta "desconstrução" do sujeito e das determinações simbólicas da subjetividade é onde a noção particular de transformação política começa a se tornar útil, mas onde também, algumas vezes, ela é chamada a assumir certos encargos.

O pano de fundo para Contingência, Hegemonia e Universalidade é o texto de Laclau e Mouffe (1985) Hegemonia e Estratégia Socialista, como parte de um "projeto democrático, antitotalitário e radical" (Butler, Laclau e Zizek, 2000 b:1). Nós devemos perguntar então se a psicanálise é parte deste projeto, ao que os três responderiam que sim. Mas devemos perguntar ainda se a psicanálise, como experiência de fala, sob transferência, a um psicanalista, é igualmente uma parte deste projeto, o que curiosamente, muda a questão de figura.

A chave psicanálise, algumas vezes latente, tematiza o encontro entre Butler, Laclau e Zizek na negatividade, determinação e particularidade do sujeito. Podemos traçar o modo como estes pontos focais tornam por vezes mais nebuloso, por vezes mais agudo as relações manifestas entre os temas da hegemonia, contingência e universalidade. Esses motivos nos convidam a um exame do modo como Butler, Laclau e Zizek assumem ou evitam o Simbólico, o Imaginário e o Real. Este exame pode ganhar em clareza e profundidade se o fizermos alternando e tensionando a chave da psicanálise como teoria social com a chave da psicanálise como teoria clínica.

\section{NEGATIVIDADE}

Nós três "concordamos" - assevera Butler no início do debate - " quanto à continuidade da promessa política contida na noção de hegemonia proposta por Gramsci” (Butler, 2000 a, p. 13). Essa noção de hegemonia na verdade uma reformulação radical da versão gramisciana - introduz uma mudança teórica no interior do marxismo relativa ao papel do estado no capitalismo. Ou seja, o "corpo de um homem armado" garante, em última instância, a mistificação da classe trabalhadora pela ideologia, nos termos de uma "guerra de posições". Entre a classe trabalhadora e a classe que estabelece as leis surge um campo intermediário: a prática cultural popular. Este é o campo chave e estratégico da contestação pois o estado está 
incluído nestas práticas assim como tais práticas servem à organização da sociedade civil. Uma classe torna-se "hegemônica" sobre outra quando ela é culturalmente dominante. Portanto a tarefa da esquerda é reconfigurar o modo no qual significantes tais como "classe" ou "nação" funcionam no interior de discursos reacionários ou progressistas abrindo assim diferentes posições para que os sujeitos às ocupem. Para Laclau, um dos teóricos deste giro, "o campo relativamente estável destas posições é que o constitui uma "formação hegemônica" (Laclau, 2000c:71).

Não há mais a lembrança, no nível do significado. Há apenas uma visada objetiva da exploração, a verdade histórica da luta de classes, para descobrir e aproveitar. Esta noção gramisciana de hegemonia veio a funcionar como premissa para a atividade política dos partidos "Eurocomunistas", quando estes se transformam, seguindo a liderança do Partido Comunista Italiano, de partidos da Terceira Internacional Comunista em organizações social democratas, mais amplas e inclusivas (Mandel, 1978).

Aqui Butler segue a indicação de Laclau. Sua leitura de Hegel é a de uma teórica da negatividade que insiste no papel crucial do sujeito no coração de cada formação hegemônica. Isso também significa que o lugar que ela atribui ao sujeito individual em uma formação hegemônica aproxima-se de uma necessária foraclusão: "todo sujeito emerge na condição de foracluído ${ }^{4}$ "(Butler, 2000 b: 140). Posteriormente ela indexará esta afirmação como uma referência a Laplanche (Butler, 2000 b:153) mais do que a Lacan. Há algumas consequiências clínicas nesta visão. Isso significa que o diagnóstico diferencial em estruturas clínicas, nas quais a psicose está indicada pela operação de foraclusão (Lacan, 1981), será agora substituída por uma atenção ao modo como todo sujeito será constituído por tal operação.

É claro que aqui há um deslocamento teórico quanto ao nível de apreensão do sujeito. Escolhas específicas tomadas pelo sujeito em relação a foraclusão, repressão ou renegação, são deslocadas para o plano de distintas "práticas discursivas" que abrem posições subjetivas. Este deslocamento aparece de forma ainda mais marcante à luz da divergência de Butler em relação a Laclau com relação a como certos "signos" ou "significantes" ${ }^{5}$ devem aparecer na vida política e pessoal: "Eu tenho menos certeza de que o signo deve ser a unidade de análise (como Laclau sugere) (...) o signo precisa ser resituado ele mesmo no interior das práticas discursivas." (Butler, 2000c, p. 271). É a atenção às posições, tornadas operativas por "práticas discursivas" conflitantes que nos dá uma imagem das identidades fluidas sobre as quais se apóiam alguns seguidores de Butler, 
Parker, I.“Teoria Social Lacaniana e Prática Clínica”

no quadro das políticas sobre homossexualismo. Uma imagem da qual ela tem tentado se livrar (Butler, 1993).

A atenção a práticas discursivas nos envia ao modo como questões colocadas ao sujeito, como constitutivas de sua estrutura, aparecem na interpelação ideológica. Por exemplo, perguntas não enunciadas tais como - sob qual lei você vive ? Você é uma mulher ou um homem ? (no caso de estrutura obsessiva ou histérica respectivamente) acabam sendo encaminhadas na forma do silêncio: "a interpelação não opera sempre pelo nome: este silêncio pode estar dirigido para você" (Butler, 2000b:157). Existem implicações em como o silêncio em análise pode ser conceptualizado pelo analista, e pelo analisante, em si isto é bastante compatível com a prática lacaniana.

\section{FEMINISMO E PSICANÁLISE}

Butler chama nossa atenção para o feminismo como um recurso teórico, e como um marco conceitual que o analista pode usar para significar a forma como ele é posicionado pelo analisante. É muito comum analisandas mulheres dirigirem-se à análise em função do quebra cabeças formado pelas questões da posição sexual e da sexualidade, questões que elas querem entender e em relação às quais a redução a manifestações da estrutura histérica não são muito úteis. Reivindicação, geralmente dirigida a homens e identificação, usualmente endereçada às mulheres.

A tomada do feminismo por Butler não está à procura de uma "feminilidade" sub-reptícia que seria tarefa da análise e retomar, celebrar e premiar, como nos escritos de Irigaray (1985), por exemplo. Isto é, menos que cair na armadilha de opor-se a Lacan, como um analista patriarcal, em nome de uma mulher que na verdade não existe, Butler está trabalhando precisamente com os modos pelos quais identidades, de todo tipo, são caracterizadas por uma "incompletude constitutiva" (Butler, 2000a: 30). Identidades que nós podemos ler facilmente como faltantes. Talvez seja em outro sentido que estas apareçam, e devam aparecer como faltantes, em sua localização cultural e política. Esta localização torna-se então parte da política da análise, e nós devemos imaginar, igualmente da análise pessoal.

Assim trata-se da recusa de uma feminilidade autêntica e essencializada e, ao mesmo tempo, da análise de como esta feminilidade é produzida como uma fantasia. Uma fantasia que governa as atividades de muitas feministas e de muitas psicanalistas feministas. Butler nos convida 
Psicologia \& Sociedade; 14 (2): 48-73; jul./dez.2002

à teoria pós-colonial para mostrar como culturas são definidas pelo que elas excluem no outro. Outro que opera como fonte de atração e horror. Sua atenção ao "ato constitutivo de translação cultural" (Butler, 2000 a:20) é retomado de Hegel - "o indivíduo no seu trabalho individual trabalha inconscientemente realizando um trabalho universal" (Spivak, 1988). O que Spivak (1988) descreve como o "discurso do subalterno" está sempre no interior de uma formação hegemônica dominante. Isso traz para o argumento de Butler uma atenção para os modos raciais como a identidade é construída dentro do simbólico. Eles não estão formados e prontos para serem trazidos à luz pela análise, mas precisam ser "desconstruídos" pela análise de discurso, mesmo se ele se apresenta como falado, declarado e explícito.

Parte do que "precisa ser desconstruído", não necessariamente no nível da análise pessoal , o que seria tomado não seletivamente, sob os parâmetros de uma dada ordem simbólica dada, é a construção de categorias analíticas elas mesmas. Por exemplo, Butler segue Zizek na análise cultural. Isto é, ela que assume a forma operacional do que ele pretende detectar: certos performativos sociais que fazem da intervenção do analista da cultura um ato. Ela pergunta, "qual é o lugar e a hora ?" desta "ação performativa".

Trata-se aqui da referência à análise exemplar feita por Zizek do filme Tubarão. Este filme isola agudamente um ponto de estofo ${ }^{6}$ para o medo livremente flutuante e inconsistente da classe média americana na década de 70. Tubarão anuncia um momento do "retorno da coisa para si mesma", tal qual especificado por Hegel .

Isso está "restrito aos poderes do nominalismo na modernidade" (Butler, 2000a:27) ? Mesmo assim ela assume certas categorias sem análises prévias. Laclau detectou em alguns argumentos de Butler um motivo igualmente universalista, a "performance". Neste contexto ele pergunta:

"seria a performance ${ }^{7}$ uma categoria vazia a ser preenchida variavelmente em diferentes contextos, ou ela é contextual-dependente, assim existiriam sociedades onde não haveria ações performativas ?" (Laclau, 200b:189)

\section{O CORPO: O FANTASMA E O SIMBÓLICO}

Para Butler o corpo é um lugar chave para a subversão social e sexual mais do que uma base neutra ou indicador de preferência sexual:

“ (...) o corpo precisa entrar na teorização da norma e da fantasia, desde que ele é precisamente o lugar onde o desejo por normas toma for- 
Parker, I. "Teoria Social Lacaniana e Prática Clínica"

ma, e onde as normas cultivam o desejo e a fantasia a serviço de sua própria naturalização" (Butler, 2000b:155).

Isso também significa que Butler está decididamente descontente com narrativas que posicionam o encontro traumático como lei do significante, necessariamente organizado pela necessária estrutura Edípica e Simbólica como a prática originária que divide e torna possível a formação da masculinidade e feminilidade. Para Butler o "postulado teórico geral da originariedade do trauma pressupõe a teoria estruturalista das relações e da sociabilidade" (Butler, 2000b:142). Para posicionar a entrada do simbólico nesta via é também pressuposto uma hetero normatividade do discurso da identidade sexual:

"O caráter formal desta originária, pré- social sexualidade na sua ostensiva vacuidade é cúmplice de uma reificação na qual uma certa idealização e um dimorfismo são sustentados." (Butler:2000b:145)

É preciso notar aqui que Butler está mais próxima de Lacan do que ela pensa. Sua crítica de Lacan está baseada em uma concepção equivocada de Imaginário como um lugar fluido de identificações, em contraste com o Simbólico estruturado pela Lei que sustenta as coisas em seus lugares (Butler, 1993). Como Zizek (1999) apontou Butler precisamente inverte a tese de Lacan acerca da fixidez do Imaginário, revelada, por exemplo, em certos sistemas delirantes da psicose que acabam "regredindo" a esta fixação imaginária, em contraste possível com uma leitura do Simbólico como um sistema de posições possíveis e arbitrárias. Há pois uma liberdade necessária interna ao simbólico assim como uma prisão insidiosa interna ao imaginário.

Mesmo assim, Zizek e Laclau, ambos encontram em seus pontos de vista, o Simbólico como um sistema cuja imagem é a de livre movimento que soa um pouco otimista demais. Em outras palavras soa tão imediata e diretamente otimista quanto o veio contemporâneo representado pelo pragmatismo liberal americano. Para Laclau é necessário desenvolver uma "análise formal da lógica" das operações de hegemonia que permitiria determinar qual espaço de movimentos é possível nesta guerra de posições. Zizek também tem um problema com a valorização que Butler faz dos agentes de resistência marginal, de forma que:

"O que Butler, deixa fora de consideração é o caminho pelo qual um estado de poder ele mesmo é dividido por dentro resiste sobre seus restos de um espectro obsceno que o sustenta" (Zizek, 2000a:313).

Zizek prossegue afirmando que Butler falha em reconhecer o caminho pelo qual um estado de poder "dividido internamente" deixa identi- 
Psicologia \& Sociedade; 14 (2): 48-73; jul./dez.2002

ficações residuais. Butler certamente tem o direito de recusar a oposição simples entre o grupo de referência para a identidade e o Estado. A resposta de Butler a esta crítica é objetar que Zizek "não explode a identidade transformando-a em algo novo" (Butler, 2000c:276).

Nós devemos dizer que a questão clínica que isso abre tem relação com a previsibilidade da velocidade da transformação em análise. Tomando o momento em que um analisante sai pela porta do consultório como referência, podemos dizer que, Zizek tende a ver a mudança pelo lado da hesitação, Butler pelo lado da precipitação. Butler abre uma visão da posição sexual que tende a concebê-la de modo flexível. Ela está ostensivamente próxima da noção de construção da posição sexual elaborada por Lacan (1975). Como Laclau aponta, Butler se atola nas suas próprias asserções acerca do caráter "performativo" da natureza humana.

Esta linha de base de asserções sobre as características universais da existência humana constitui uma espécie de assombração no debate entre os três. Assombração que irá reaparecer na forma daquilo que "deve sempre" ser encontrado no final de uma análise, por qualquer um que tenha feito uma análise. Isso será visto quando abordarmos a tese de Zizek acerca da efetividade do Real no ato analítico. Antes disso, voltemo-nos para o que Laclau oferece ao debate e talvez, ao trabalho clínico.

\section{DETERMINAÇÃO}

Laclau e Mouffe (1985) desenvolveram a tese de Gramsci sobre a hegemonia na sociedade capitalista em contraposição direta à tese da ideologia no marxismo tradicional. A teoria da hegemonia no trabalho de Laclau assume também algumas coordenadas lacanianas da discussão feita por Althusser (1971) acerca da psicanálise em relação com a análise política. Laclau pode ser lido então, primariamente, como um teórico centrado na questão da estruturação do Simbólico, ou sobre como o Simbólico produz posições para serem ocupadas por sujeitos específicos - nos termos de Althusser, emprestados de Marx, as "sustentações" ou "suportes" da estrutura social. De toda forma, o que Lacan produz em Laclau não é uma tese sobre a sociedade, mas uma tese teoricamente elaborada sobre a sua dissolução. Isso significa encontrar em Lacan o que "efetivamente se traduz pelo caráter cindido de qualquer objeto de identificação - o que Laclau chama de impossibilidade última da sociedade" (Stavrakakis, 1999:39). Se a asserção de Laclau, de que não existe tal coisa como a sociedade, soar estranha e perturbadoramente próxima da visão que Margareth Tatcher tem 
Parker, I.“Teoria Social Lacaniana e Prática Clínica”

sobre a matéria (Homer, 1999), isso nos apontará para outro elemento da teoria lacaniana com qual Laclau parece estar preocupado, mas não demasiadamente: o Imaginário. Há uma questão correndo em torno dos escritos de Laclau - desde a retomada do conceito de hegemonia, com Moufee (1985) até o debate com Zizek e Butler - acerca da determinação do sujeito e a relação entre a "análise formal da lógica" da identificação político social.

Contra a universalização da "paródia performativa" de Butler, como espaço de negatividade relacionado ao Simbólico, Laclau posiciona seu próprio universal: "a sociedade organizada como um espaço retórico" (Laclau, 2000c:78). O social, quando conceitualizado como uma formação hegemônica, parece flutuar da atividade de indivíduos movendo-se através disso e perseguindo isso, como se Laclau, assim como Butler, estivessem operando com o Simbólico, como algo que mantém as coisas em seus lugares que são então reproduzidos ou transformados pela atividade em um outro registro: o das atividades locais do dia-a-dia. Laclau descreve, por exemplo, "dois diferentes modos :" "universalização" e "particularização" que compõe a hegemonia, articulando a totalidade, (Laclau, $\left.2000^{a}: 302\right)$. Sua concepção de linguagem é a de um espaço que é suficientemente fluido para manter as relações e para autorizar sua transformação; "o conjunto de regras, mais as ações que implementam/distorcem/subvertem essas regras é o que nós chamamos de "discurso" (Laclau, 2000a:284).

Uma tese acerca do projeto político elaborado por Laclau e Mouffe carrega o subtítulo "o imaginário radical democrático" (Smith, 1998), e está bem colocado porque o livro captura algo da promessa do espaço Imaginário contra o Simbólico que Laclau detesta, citando o como um "exemplo cru" daquilo que "confunde análise do concreto com o meramente factual ou relato jornalístico" (Laclau, 2000c:87). Parece que para Laclau ser "sociológico" ou "descritivo" é tão ruim quanto ser "empirista" como o que ele detecta na obra de Butler. Não queremos dizer que Butler permanece na fronteira do Imaginário, mas que seu trabalho está preocupado com as formas pelas quais a identificação pode ser evitada através de uma elaboração teórica. Quais são as implicações analíticas desta proposta ?

\section{IDENTIFICAÇÃO E IDENTIDADE}

Laclau olha para um "horizonte de inteligibilidade" do social que não é governado pela topografia, mas pela lógica (Laclau, 200c:58), e ele indexa esta oposição a oposição entre Estado e Sociedade Civil. Alguém 
poderia assinalar que é exatamente este o espaço onde se localiza a prática psicanalítica, enquanto prática social. Além disso, de forma paradoxal, levando em conta o lugar da identificação nos escritos de Laclau, isso nos autoriza a uma distinção: de um lado a fala do sujeito concernente as suas "topografias" e os assuntos de "Estado", que nós podemos interpretar como colados à linha do Imaginário-manifesto. Talvez isso seja uma forma de fazer diretamente observáveis as políticas de identificação e alianças que constituem matéria do diálogo psicanalítico.

De outro lado a "lógica" que serviria para mapear as posições na "sociedade civil" que o sujeito ocupa, posições governadas pelo Simbólico. As formas do "laço social" especificadas por Lacan (1991) na discussão dos quatro discursos, por exemplo, simultaneamente localizam o sujeito em estruturas sociais (burocracia e educação) e na sessão analítica (da histeria e do analista). Esta especificação do laço social é também um dos pontos nos quais Lacan estava elaborando "matemas" que precisamente mapeariam a posição do sujeito em termos lógicos. A proposta de Laclau, no nível social, então é plenamente compatível com o modo como o analista pode "girar" da "compreensão" do analisante - a "significação" de sua fala na relação imaginária - para a "formalização" do sintoma e a direção do tratamento - a estrutura da fala no interior do simbólico.

Laclau toma uma posição contraria a qualquer forma de "política de identidade", sem eventualmente nem mesmo entrar em considerações estratégicas que são apreciadas por Butler em relação a esta forma de política. Isso não significa que ele dispensa a identidade como uma ferramenta da análise política. De fato, uma parte do giro da análise de classes, do marxismo tradicional, para a "pós-marxista" análise de discurso e de formações hegemônicas está baseada precisamente na redução da consciência de classe à identidade. Portanto, em oposição a Zizek, Laclau reafirma seu argumento de sempre "luta de classes é apenas uma espécie de identidade política, uma que se torna menos e menos importante no mundo em que nós vivemos hoje em dia" (Laclau, 2000b:203). Novamente podemos ver uma oposição sendo criada entre uma concepção de sociedade que foi erguida pela obsessão política tradicional com as "relações de produção" (incluindo o marxismo) e uma outra esfera de ação na qual a as políticas de identidade são formadas; "antagonismos entre classes ... toma lugar entre estas relações de produção e a identidade dos trabalhadores fora delas" (Laclau, 2000b:202). Mais uma vez é possível detectar nesta oposição a oposição entre o estruturalmente determinado, a ordem Simbólica, e um campo mais fluido e livre - o Imaginário. Laclau não quer 
Parker, I. “Teoria Social Lacaniana e Prática Clínica”

realmente abandonar a arena das políticas de identidade em troca de uma ação no nível simbólico; mais do que isso ele nos adverte contra uma série de novas políticas de identidade que podem ser mobilizadas contra e em vez da identidade de classe: "A noção de 'desenvolvimento combinado e indecidido" ${ }^{8}$ " tem apontado para a emergência de complexas e não ortodoxas políticas de identidade e instâncias revolucionárias de mudança. “ (Laclau, 2000b:203).

Alguém pode imaginar uma estratégia analítica que destruiria as formas de política de identidade usadas pelo analisante, entendendo-as como formas de defesa. O erro, no que concerne a Laclau, falando agora como analista lacaniano, é assumir uma sub-identidade que precisa ser descoberta e escorada. A análise não abole as identificações imaginárias que constituem a identidade mas as reconfigura de forma a que o sujeito reconheça a forma como elas operam. As coisas seriam um pouco diferentes no caso de um analisante de estrutura psicótica, para quem escorar ${ }^{9}$ o sistema delirante seria a opção preferencial no tratamento psicoterapêutico em oposição ao trabalho analítico. Laclau, assim como Butler, descrevem o social como compreendendo sujeitos neuróticos, não psicóticos, e como indiferenciados em termos de estrutura histérica ou obsessiva. É, como argumenta Laclau, a distinção formal entre significante e significado que nos "autoriza a exploração do inconsciente e destacar esta exploração da busca do sentido último" (Laclau, 2000c:69).

\section{ANÁLISE PESSOAL COMO LIÇÃO POLÍTICA}

Nesta visão, portanto, há uma simetria quase perfeita entre a análise pessoal e a produção de um sujeito que será funcional em uma sociedade democrática. De fato, para Laclau, o abandono da busca pela última significação é uma espécie de senha para políticas democráticas assim como é para a psicanálise: "A única sociedade democrática é a que permanece sempre mostrando a contingência de suas próprias fundações - nos nossos termos, permanentemente mantém aberto o intervalo entre o momento ético e a ordem normativa" (Laclau, 2000c:57). Neste ponto, Butler está com Laclau, e ela apresenta sua posição em termos muito próximos da dele: "Paradoxalmente ... a democracia é segurada pela sua resistência a realizar-se." (Butler,2000c:268)

Enquanto Laclau teoriza o social em termos "lógicos" ele toma precauções contra a adoção de metanarrativas, e nisso, é claro, ele está muito próximo dos "pós-marxistas" e dos "pós-modernos" e sua valoriza- 
Psicologia \& Sociedade; 14 (2): 48-73; jul./dez.2002

ção dos jogos de linguagem no lugar do entendimento dos processos históricos. Pode-se argumentar que não é possíveis conceitualizar o que acontece nos processos históricos e o nosso lugar neles sem algum tipo de metanarrativa teórica e que não é possível conceitualizar o que acontece nos processos histéricos de questionamento em análise e o nosso lugar neles sem empregar algum tipo de metanarrativa para tal. O reconhecimento de que "não há metalinguagem" e que não há "Outro do Outro", de que não há "relação sexual" é muito diferente da recusa de um aparato teórico do qual se faz uso na direção do tratamento, como se o analisante chegasse a todas as constatações analíticas absolutamente por si mesmo. Como Zizek argumentou "é preciso algum tipo de metanarrativa que explique esta passagem do essencialismo para a consciência da contingência" (Zizek, 2000c:106).

Zizek também objeta um pressuposto político que aparece nas teses de Laclau, e o que elas obscurecem. É exatamente a redução da "luta de classes" à "identidade" aquilo que ele deplora: "nesta súbita suspensão da análise de classes ... nós estamos lidando com um caso exemplar do mecanismo do deslocamento ideológico." (Zizek, 2000c:97). A objeção de Zizek chama a atenção, em último caso, para o fato de que a direção do tratamento torna se, na visão de Laclau, um espelho perfeito demais de sua visão política: política pósmoderna "de fato não repolitiza o capitalismo, porque a noção de forma da política no seu interior opera despolitizando a economia" (Zizek, 2000c:98). Talvez o problema aqui não seja a direção do tratamento na análise, até aqui o trabalho de Laclau traduz-se em uma prática perfeitamente compatível com a psicanálise lacaniana, o erro está no espelhamento assumido entre o campo da análise pessoal e o campo da ação política.

Este espelhamento fecha o intervalo entre dois campos, e assim fecha o intervalo que faz a mudança pessoal e a ação política possível. A obra de Laclau não leva explicitamente em conta a disparidade, ou o espaço, entre o que o analisante vem a descobrir sobre suas representação e a ação política que se abre para ele para lidar com a desigualdade social. Um ato analítico pode corresponder a um ato social, mas será a diferens $a^{10}$ entre os dois que torna cada um deles possível. Para desenvolver algum tipo de metanarrativa que nos autorize a avançar é preciso um giro para o Real e para a particularidade do sujeito.

PARTICULARIDADE DO SUJEITO 
Parker, I."Teoria Social Lacaniana e Prática Clínica"

Zizek acusa Butler e Laclau de serem "secretamente kantianos", isto, é "ambos propõe um modelo apriori formal e abstrato (de hegemonia, de performatividade de gênero ...) e isso nos conduz a um processo sem fim de deslocamentos parciais" (Zizek, 2000c:111). A tese mais forte sobre as formações hegemônicas que Laclau emprega para desenvolver "uma lógica" portanto, aprisiona-o em um horizonte limitado, um relato abstrato da "democracia radical" que está necessariamente cego para a luta de classes que pode por de lado uma formação hegemônica que pertence à sociedade capitalista. Zizek escreve como um tático que operou em inúmeras peças e variedades de formações hegemônicas, por um tempo como escritor de discursos para stalinistas, quando estes estavam no poder na Eslovênia, em seguida como membro ativo na liderança do Partido Liberal Democrata, de oposição inicialmente e em seguida governando um novo mercado livre administrando uma "terapia de choque" na economia Eslovena (Boynton, 1998).

A surpreendente posição que ele adota no debate com Butler e Laclau é que ele é o único querendo abrir os termos do debate para além dos limites formais e abstratos da sociedade capitalista. Ele quer trazer uma forma diferente de "historicidade" que irá ligar Lacan com Marx. Assim, como se opondo ao historicismo que procura pelo lugar das substituições no interior de um mesmo campo fundamental de substituições, que é o que Zizek acusa em Butler e Laclau "historicidade propriamente faz diferenças temáticas, segundo diferentes princípios estruturais de sua (im)possibilidade" (Zizek, 2000cc:112).

Zizek toma como modelo de "princípios estruturais" de (im)possibilidade o dito de que não há tal coisa como a relação sexual (Lacan, 1975:12). Como Zizek saliente, para Lacan, "qualquer tradução da diferença sexual em um campo de oposições simbólicas está fadado ao fracasso, e é esta" "impossibilidade" que abre o terreno para a luta por hegemonia em torno "do sentido da "diferença sexual" (Zizek, 2000c:111). Isso ocorre porque a diferença sexual "resiste a ser simbolizada" (Zizek, 2000:111). Essa tese difere da de Butler no sentido de que ela posiciona a diferença sexual como um "dimorfismo" fundado em um encontro traumático (como vimos antes, ela alega que isso torna restritas as possibilidades de subversão radical e transformação da posição sexual e da sexualidade), isso a diferencia de Laclau pois restringe a impossibilidade do Real a impossibilidade da divisão sexual". 
O NÚCLEO TRAUMÁTICO DO REAL

Menos do que restringir esta "impossibilidade" apenas ao sexo, Zizek o indexa ao clássico estudo de Levi-Strauss (1963) sobre a tribo Winnebago do Canadá. Se um grupo na tribo for convidado a produzir uma representação da tribo eles desenham um círculo com outro circulo no seu interior, indicando a posição de um grupo cercado pelo outro. Se o outro grupo for chamado a fazer uma representação da tribo, eles desenham um círculo com uma linha no centro, indicando os dois grupos lado a lado. Isso capta perfeitamente o modo como as desavenças entre os grupos acontecem, e também como esta desavença emana também sobre quais são os termos que constituem a desavença o que ainda ilumina, elegantemente, as querelas entre mulheres e homens. O diagrama de Lacan (1975) sobre a sexuação capta justamente esta disparidade de representações sobre a diferença sexual. Essa é uma diferença que é, como Zizek assinala, uma impossibilidade constitutiva de representação e Levi-Strauss mostra a "referência escondida neste 'núcleo traumático constante' , um antagonismo fundamental" (Zizek, 2000:112).

Esse núcleo traumático do real é referido por Levi-Strauss como a "instituição zero", e Zizek extrapola isso ao falar da "zero-instituição" da "nação" e da "diferença sexual" (Zizek, 2000c:114). Zizek se refere às teses de Hardt e Negri sobre o capitalismo contemporâneo como muito próximas ao "modelo de uma análise" (Zizek, 2000b:239) e é o capitalismo que eles tomam como matriz fundamental para o encontro traumático do sujeito com o real, que ele encontrará presumivelmente de novo, na própria análise. De toda forma, é preciso notar sua citação entusiasmada da asserção que "as melhores experiências subjetivas são os piores e mais reacionários argumentos" (Deleuze,1995:11 ${ }^{11}$ ). Para Zizek "uma história de vida pessoal, diz, como bricolage das últimas tentativas de por termo a algum trauma" (Zizek, 2000c:125), e o trauma que ele sinaliza é o ponto de impossibilidade que é suturado nos escritos de Laclau e Butler é a classe. Isso traz um número de questões acerca de como a psicanálise deve proceder se ela girar sua atenção da diferença sexual para a diferença de classe como um "centro traumático" do real que precisa ser encontrado pelo sujeito.

Nisso precisaríamos ter alguma idéia de como se podem interpretar os deslocamentos de classe, como Zizek parece ver no tratamento psicanalítico padrão, porque ele é um deslocamento como defesa. Ele é caracterizado como um mecanismo ideológico. Podemos então ler o "des- 
Parker, I.“Teoria Social Lacaniana e Prática Clínica”

locamento ideológico" operando em cada sujeito individual na análise, no capitalismo ? Poderíamos então entender a "não relação" entre analisante e analista como indicativo de um beco sem saída representacional que foi determinado pela diferença de classe mais do que pela diferença sexual ? Isso requer um tipo diferente de "diagrama da luta de classe" que permitiria reconfigurar o diagrama lacaniano da sexuação ?

Pode igualmente parecer axiomático se nós reflexivamente situássemos nós mesmos na relação com o analisante como uma não-relação. O modo pelo qual o beco sem saída é formalizado pelo analista será por sua vez diferente da forma como será formulado desde a posição de analisante. $\mathrm{O}$ que o diagrama da sexuação indica é que as regras que comandam as desavenças sobre como o diagrama deve ser interpretado, são interpretadas diferentemente em cada lado. Devemos então dizer que esta dificuldade necessária de interpretação diz respeito á "diferença absoluta" , como um fim de análise entre analisante e analista assim como uma "diferença absoluta" na concepção que o analisante tem do jogo significante. (Lacan, 1973:276). No argumento de Zizek chama a atenção o fato de que um relato diferente pode ser dado do final de uma análise, pelo analista e pelo analisante - um fenômeno levado seriamente em questão nas discussões atuais sobre o "passe" pelo qual um relato é dado a uma Escola de psicanálise no fim de uma análise (Dunand, 1995).

Zizek (1999) indicou em outro lugar sua dificuldade com a leitura de Jacques Alain Miller que especifica em termos da sexuação o encontro com o Real que caracterizaria o final da análise. Para Zizek, a redução da diferença entre homem e mulher opera no interior de um ponto de vista histórico acerca das relações entre os sexos. A sua própria especificação de "luta de classes" como um ponto chave também pode ser defendido como uma apropriação ao capitalismo, como um núcleo histórico traumático, mas isso ainda orientaria o analista, e o analisante na direção do tratamento, a um fim de análise particular, e a um tipo particular de ato analítico.

\section{O ATO ANALÍTICO}

Zizek descreve "o ato" como o que se deve esperar ocorrer na análise como "um gesto que por definição, toca uma dimensão possível do Real." (Zizek, 2000c:121). Mas a forma como ele elabora esse ato na sua relação com um ato que perturbaria o social, porque toca no Real de uma estruturação antagonística abre um número de questões pelas quais a aná- 
$\overline{ }$ Psicologia \& Sociedade; 14 (2): 48-73; jul./dez.2002

lise individual se conecta com análise social no nível da transformação do mundo, além de simplesmente sua interpretação. "Um ato autêntico" , argumenta Zizek (2000,2000:124), perturba umas fantasias sub-reptícias, atacando-a do ponto de vista do "sintoma social" (Zizek, 2000c:124) e aqui Zizek está se referindo à travessia do fantasma fundamental que sustenta o sujeito em um lugar, de tal forma incrustado, que tal ato terá conseqüências na sua localização social. Isto é, o final da análise, no qual o analisante atravessa sua fantasia que o fascinou e imobilizou pode ser visto como estritamente equivalente a um tipo de intervenção que um ativista político deve fazer em uma formação hegemônica que estrutura o fantasma daqueles que vivem submetidos a ela.

Isso também significa que com respeito à direção do tratamento, o analista será levado no seu fim a um relato teórico acerca de como o analisante, como um ator político proletário, fala, mais do que simplesmente como sujeito masculino ou feminino na relação com a sexuação, ou com um ato "autêntico" ou "inautêntico". Zizek propõe a sua própria distinção entre um ato de esquerda (que toma o Real de um antagonismo atravessando o social) e um ato fascista (que requer o falseamento da localização do antagonismo, ao modo corporativo, fora do social, não aceitando o real antagonismo no seu interior).

Laclau objeta a Zizek em três pontos: ele vê a classe como necessariamente universalizada, que ele adere a um modelo base/superestrutura, e que ele faz uma diferença estrita entre lutas contra o sistema e as lutas internas ao sistema. Adicionalmente, Laclau aponta que o capitalismo não pode ser o Real, como Zizek argumenta, porque ele opera como uma parte do simbólico. O real lacaniano é o que resiste á simbolização. Butler, por sua vez, objeta ao que ela detecta como um motivo kantiano em Zizek, a sua insistência de que a estrutura que ele descreve é anterior aos relatos que se pode extrair sobre ela; "não se pode identificar tais estruturas formais e depois aplicá-las aos exemplos, por exemplo as suas" aplicações "se tornam algumas coisas outra em relação ao que elas eram" (Butler, 200a:26). A acusação de que Zizek lança contra Butler e Laclau retorna como uma assombração contra ele mesmo e sua insistência na luta de classes como antagonismo fundamental que deve ser levado em conta em qualquer forma de análise é reduzido ao fetiche em torno do qual sua própria "metanarrativa" está envolvida. 
Parker, I."Teoria Social Lacaniana e Prática Clínica”

\section{O QUE É ESQUERDA ?}

É difícil situar e acessar as posições políticas advogadas por estes três teóricos da sociedade assim como extrair consequiências clínicas de seus vários argumentos (Roberts, 2001) Butler se engajou em um público neofeminista que é igualmente suspeito de essencializar a feminilidade, e Laclau tem uma repercussão similar para uma audiência "pós-marxista", acostumada à verdade crua sobre a história e a economia. Em ambos, de toda forma, é exatamente sua recusa à posição política automática é o que os previne contra a elaboração de um programa de transformações, assim eles se engajam em iniciativas locais já existentes. Mesmo Zizek, que flanqueia os outros dois desde uma retórica de esquerda mais ostensiva e ortodoxamente marxista, é muito escorregadio ao se posição em relação à política marxista (Homer, 2001).

Talvez seja esta grande indeterminação acerca de um programa político o que torne estes três pensadores compatíveis com a psicanálise lacaniana. Nós não tentamos "entender" o que um paciente está nos dizendo, e nós não "interpretamos" para ele o sentido do que ele está dizendo. Menos ainda o educamos para ver o mundo como nós o vemos. A "diferença absoluta" precisa incluir a diferença sobre perspectivas políticas, mesmo quando o reconhecimento de diferenças em perspectivas políticas vem a ser uma orientação sobre como alguém se aproxima da política.

A grande diferença de perspectivas políticas entre Butler, Laclau e Zizek parece indicar que a prática psicanalítica com indivíduos não pode ser lida facilmente no beco sem saída da representação. De fato a "impossibilidade" precisa ser conceitualizada. Os três parecem crer na existência de um abismo não ultrapassável. Mas não seria apropriado, em nenhum caso, detectar o Real sob as posições políticas de Butler, Laclau ou Zizek e então especular sobre como essa posição jogaria o seu papel na análise e fora dela. O Real sob as posições políticas é mais algo a ser desistido do que algo a ser refundado. Alguém pode dizer que uma lição inteiramente compatível com a análise lacaniana que estes três autores oferecem é que uma "posição política" sustenta o sujeito em um lugar enquanto ela oferece ao sujeito uma maneira de sair deste lugar.

Com relação ao final da análise e o funcionamento do objeto a, "cortando o excesso deste precioso objeto por cuja posse o inimigo coloca-o em xeque, o sujeito recebe espaço para ação livre." (Zizek,2000c:122). Se, somente neste ponto de desistir daquilo que nos mantém enfeitiçados, nos tornando capazes de fazer algo diferente com nossas vidas, então nós, 
Psicologia \& Sociedade; 14 (2): 48-73; jul./dez.2002

talvez, sejamos diferentes também. É a este respeito que Butler, Laclau e Zizek ligam o pessoal e o político provocando o pensamento e a teoria social no campo da prática clínica.

\section{REFERÊNCIAS BIBLIOGRÁFICAS}

. ALTHUSSER, L. Lenin and Philosophy, and Other Essays. London: New Left Books, 1971.

. BOYNTON, R. S. "Enjoy Your •i•ek!: An Excitable Slovenian Philosopher Examines The Obscene Practices of Everyday Life Including His Own", Linguafranca: The Review of Academic Life, 7, (7), http://www.linguafranca.com/9810/zizek.html , 1998.

. BURGIN, V., DONALD, J. AND KAPLAN, C. (eds) (1986) Formations of Fantasy. London: Methuen.

. BUTLER, JGender Trouble: Feminism and the Subversion of Identity. London: Routledge.

. BUTLER, J. Bodies that Matter. London: Routledge, 1986.

. BUTLER, J. "Restaging the Universal: Hegemony and the Limits of Formalism", in J. Butler, E. Laclau and S. •i•ek Contingency, Hegemony, Universality: Contemporary Dialogues on the Left (pp. 11-43). London: Verso., 2000a

. BUTLER, J. "Competing Universalities", in J. Butler, E. Laclau and S. - $\cdot \bullet \mathrm{ek}$ Contingency, Hegemony, Universality: Contemporary Dialogues on the Left (pp. 136-181). London: Verso, $2000 \mathrm{~b}$.

. BUTLER, J. "Dynamic Conclusions", in J. Butler, E. Laclau and S. •i•ek Contingency, Hegemony, Universality: Contemporary Dialogues on the Left (pp. 263-280). London: Verso, 2000c.

. BUTLER, J., LACLAU, E. AND •I•EK, S. Contingency, Hegemony, Universality: Contemporary Dialogues on the Left. London: Verso, 2000a.

. BUTLER, J., LACLAU, E. AND •I•EK, S. "Introduction", in J. Butler, E. Laclau and S. • i•ek Contingency, Hegemony, Universality: Contemporary Dialogues on the Left (pp. 1-4). London: Verso, $2000 \mathrm{~b}$.

. DELEUZE, G. Negotiations. New York: Columbia University Press. 1995. 
Parker, I."Teoria Social Lacaniana e Prática Clínica"

. DUNAND, A. "The End of Analysis (II)", In R. Feldstein, B. Fink and M. Jaanus (eds) Reading Seminar XI: Lacan's Four Fundamental Concepts of Psychoanalysis. (pp. 251-256). New York: SUNY Press, 1995.

. FINK, B. A Clinical Introduction to Lacanian Psychoanalysis: Theory and Technique. Cambridge, MA: Harvard University Press, 1997.

. HARDT, M. AND NEGRI, A. Empire. Cambridge, MA: Harvard University Press, 2000.

. HEGEL. G.W.F. Science of Logic. Oxford: Oxford University Press, 1969.

. HENRIQUES, J., HOLLWAY, W., URWIN, C., VENN, C. AND WALKERDINE, V. (1984) Changing the Subject: Psychology, Social Regulation and Subjectivity. London: Methuen, 1984.

. HOMER, S. Psychoanalysis, representation, politics: on the (im)ossibility of a psychoanalytic theory of ideology? The Letter: Lacanian Perspectives on Psychoanalysis, 7, pp. 97-109, 1996.

. HOMER, S "It's the Political Economy Stupid! On •i•ek's Marxism", Radical Philosophy, 108: 7-16

. IRIGARAY, L.) The Sex Which Is Not One. Ithaca: Cornell University Press, 2001.

. JACOBY, R. "The politics of subjectivity: Slogans of the American New Left". New Left Review, 79, pp. 37-49, 1973.

. LACAN, J. The Four Fundamental Concepts of Psycho-Analysis (The Seminar of Jacques Lacan, Book XI 1964), translated by Alan Sheridan, 1979. Harmondsworth: Penguin, 1973.

. LACAN, J. On Feminine Sexuality, The Limits of Love and Knowledge, 1972-1973: Encore, The Seminar of Jacques Lacan, Book XX, translated with notes by Bruce Fink, 1998, New York: Norton, 1975.

. LACAN, J. The Psychoses: The Seminar of Jacques Lacan, Book III 1955-1956, translated with notes by Russell Grigg, 1993. London: Routledge, 1981.

. LACAN, J. The Other Side of Psychoanalysis: The Seminar of Jacques Lacan, Book XVII 1969-1970, translated with notes by Russell Grigg. unpublished ms, 1991. 
Psicologia \& Sociedade; 14 (2): 48-73; jul./dez.2002

. LACLAU, E. New Reflections on The Revolution of Our Time. London: Verso, 1990.

. LACLAU, E. "Constructing Universality" in J. Butler, E. Laclau and S. $\cdot \mathrm{i} \bullet \mathrm{e}$ k Contingency, Hegemony, Universality: Contemporary Dialogues on the Left (pp. 281-307). London: Verso, 2000a.

. LACLAU, E. "structure, History and the Political" in J. Butler, E. Laclau and S. • i•ek Contingency, Hegemony, Universality: Contemporary Dialogues on the Left (pp. 182-212). London: Verso, $2000 \mathrm{~b}$.

. LACLAU, E. "Identity and Hegemony: The Role of Universality in the Constitution of Political Logics", in J. Butler, E. Laclau and S. •••ek Contingency, Hegemony, Universality: Contemporary Dialogues on the Left (pp. 44-89). London: Verso, 2000c.

. LACLAU, E. AND MOUFFE, C. Hegemony and Socialist Strategy. London: Verso, 1985.

. LASCH, C. The Culture of Narcissism. New York: Norton, 1978.

. LEADER, D. (1996) Why Do Women Write More Letters Than They Post? London: Faber and Faber, 1996.

. LEADER, D. Promises Lovers Make When It Gets Late. London: Faber and Faber, 1997.

. LEVI-STRAUSS, C. "Do Dual Organizations Exist?", in Structural Anthropology (pp. 131-163). New York: Basic Books, 1963.

. MACCANNELL, J. F. Figuring Lacan: Criticism and the Cultural Unconscious. Beckenham, Kent: Croom Helm, 1986.

. MACEY, D. Lacan in Contexts. London: Verso, 1988.

. MANDEL, E. From Stalinism to Eurocommunism: The Bitter Fruits of 'socialism in One Country”. London: New Left Books, 1978.

. MITCHELL, J. Psychoanalysis and Feminism. Harmondsworth: Pelican, 1974.

- NOBUS, D. Jacques Lacan and the Freudian Practice of Psychoanalysis. London: Routledge, 2000.

. ROBERTS, J. Review of Contingency, Hegemony, Unversality. Radical Philosophy, 105: 48-51, 2001. 
Parker, I. "Teoria Social Lacaniana e Prática Clínica”

. ROWBOTHAM, S., SEGAL, L. AND WAINWRIGHT, H. Beyond the Fragments: Feminism and the Making of Socialism. Newcastle and London: NSC/ICP, 1979.

. SMITH, A. M Laclau and Mouffe: The Radical Democratic Imaginary. London: Routledge, 1998.

. SPIVAK, G. C. "Can the Subaltern Speak?". In C. Nelson and L. Grossberg (eds) Marxism and the Interpretation of Culture. Urbana: University of Illinois Press, 1988.

. STAVRAKAKIS, Y. Lacan and the Political. London: Routledge, 1999.

. YOUNG, R. MMental Space. London: Process Press, 1994.

. ZARETSKY, E. Capitalism, the Family and Personal Life. London: Pluto Press, 1976.

. - •EK, S. "Beyond Discourse-Analysis". Appendix in E. Laclau (1990) New Reflections on The Revolution of Our Time (pp. 249-260). London: Verso, 1990.

. $\cdot$ I•EK, S. The Ticklish Subject; The Absent Centre of Political Ontology. London: Verso, 1999.

. - •EK, S. "Holding the Place" in J. Butler, E. Laclau and S. • • ••ek Contingency, Hegemony, Universality: Contemporary Dialogues on the Left (pp. 308-329). London: Verso, 2000a.

. $\cdot \mathrm{I} \bullet \mathrm{EK}$, S. "De Capo senza Fine", in J. Butler, E. Laclau and S. •i•ek Contingency, Hegemony, Universality: Contemporary Dialogues on the Left (pp. 213-262). London: Verso, 2000b.

• •I•EK, S. "Class Struggle or Postmodernism? Yes, please!" in J. Butler, E. Laclau and S. •i・ek Contingency, Hegemony, Universality: Contemporary Dialogues on the Left (pp. 90-135). London: Verso, 2000c.

NOTAS

${ }^{1}$ Tradução: : Christian Ingo Lenz Dunker, Professor do Mestrado em Psicologia da Universidade São Marcos.

2 "ur-psychoanalyttic"

3 "Disawowal" , "Verleugnung" em alemão, tem sido traduzido por recusa (conforme o Vocabulário de Psicanálise de Laplanche e Pontalis) 
$=$ Psicologia \& Sociedade; 14 (2): 48-73; jul./dez.2002

mas também admite-se a tradução por renegação.

4 "Foreclosure" em alemão "Verwerfung" tem sido traduzido por foraclusão.

${ }^{5}$ Outro aspecto do esquecimento de Lacan aparece neste caso. Há uma elisão destes dois termos no debate entre ambos.

${ }^{6}$ N.T. "Point de capiton" no original.

${ }^{7}$ N.T. "performance"

${ }^{8}$ N.T. "uneven" no original.

${ }^{9}$ N.T. "shore up" no original.

${ }^{10}$ N.T. "différance", conforme o termo sugerido por Derrida e a opção geralmente encontrada entre seus tradutores: diferensa.

${ }^{11}$ Citado por Zizek, nota 9:328.

Ian Parker é professor do Curso de Psicologia da Universidade Metropolitana de Manchester, Inglaterra. Editor do Annual Review of

Critical Psychology é autor e organizador de diversos livros e inúmeros artigos envolvendo Teoria Crítica, Psicanálise, Análise de Discurso e Psicologia Social. Entre eles se destacam Desconstructing Psychoterapy, (Sage, 1999), Desconstructing Psychopathology (Sage, 1995), Psychology Discurse Practice - from regulation to resistence (Sage, 1996) e Culture of Psychoanalysis (Sage, 2000). Ian Parker Endereço(s) de correio eletrônico(s): I.A.Parker@mmu.ac.uk Ian Parker, Professor of Psychology, Discourse Unit, Department of Psychology and Speech Pathology, Manchester Metropolitan University, Elizabeth Gaskell Campus, Hathersage Road, Manchester, M13 OJA UK. (tel: +44 161247 2573) (fax: +44 1612476364$)$

http://www.did.stu.mmu.ac.uk/psy speech/research/discourse/ discu.htm

Agradecimentos

Obrigado a Erica Burman, Eugenie Georgaca e Sean Homer pelos seus úteis comentários na leitura dos rascunhos deste artigo.

Ian Parker

Teoria Social Lacaniana e Prática Clínica

Recebido: 16/12/2002

$1^{\text {a }}$ revisão: $29 / 1 / 2002$

Aceite final: 31/1/2003 